\title{
Afeganistão, combate ao terrorismo e "GUerra Justa". REFLEXÕES À LUZ DO DIREITO INTERNACIONAL E NA OBRA DE Francisco de Vitória.
}

\author{
Afghanistan and the fight against terrorism and just war. \\ Reflections from the light international law and the work of \\ Francisco de Vitoria.
}

\begin{abstract}
AndRé Regis
Professor e Coordenador do Curso de Direito da Fundação Cultural Dr. Pedro Leopoldo - FPL; Advogado; Membro e Vice-Presidente da Comissão de Educação Jurídica da $\mathrm{OAB} / \mathrm{MG}$ - CEJ-OAB/MG, Membro Julgador da $8^{\mathrm{a}}$ Turma do Tribunal de Ética e Disciplina da OAB/MG - TED-OAB/MG; Membro do Instituto dos Advogadpos de Minas Gerais - IAMG; Doutorando em Direito pela Pontifícia Universidade Católica de Minas Gerais - PUC/MG.
\end{abstract}

RECEBIDO EM: 23.08.2012

APROVADO EM: 05.12.2012

\section{RESUMO}

O Afeganistão foi admitido na ONU na década de 40, tendo assumido o compromisso de cumprir a Carta das Nações Unidas. Envolto em conflitos internos e externos nas décadas de 70 e 80 , assumiu o controle da maior parte do território afegão os Taliban, grupo islâmico que permitiu a proliferação no Afeganistão de grupos radicais islâmicos. Neste período, terroristas e grupos terroristas, como a Al-Qaeda, Osama Bin Laden e seus associados, instalaram, no território afegão e sem combate do governo Taliban, bases para a estruturação de células terroristas, treinamento de terroristas e planejamento de ataques terroristas. O Conselho de Segurança da ONU, invocando o Capítulo VII da Carta das Nações Unidas, por mais de uma vez exigiu do governo Taliban, dos terroristas e dos grupos terroristas, o respeito ao Direito Internacional, a Carta das Nações Unidas e as suas Resoluções contra o terrorismo. Nada foi feito pelas partes sobre a matéria. Após o ataque de 11 de setembro de 2001 nos EUA, ocorreu a intervenção militar no Afeganistão. Os EUA invocou o art. 51 da Carta das Nações Unidas para justificar a ação militar. O Conselho de Segurança reconheceu o direito de autodefesa em caso de terrorismo. Seguindo a Teoria da 
Guerra Justa, é legítimo o conflito armado quando o uso da força se constitui meio de defesa, forma de garantir a paz e a segurança e alternativa necessária para fazer frente ao inimigo. No caso da intervenção no Afeganistão, o Direito Internacional, a Carta das Nações Unidas e as Resoluções do Conselho de Segurança, que condenavam e continuam condenando o terrorismo e reconhecem o direito de autodefesa, individual ou coletiva, sempre foram descumpridas pelo governo Taliban, a Al-Qaeda, Osama Bin Laden e seus associados. Por outro lado, segundo as Resoluções do Conselho de Segurança, combater o terrorismo é um dever dos Estados-membros da ONU, conforme o Direito Internacional, a Carta das Nações Unidas e as Resoluções do próprio Conselho de Segurança, por ser o terrorismo um ato contra toda a comunidade internacional. Garantindo, pela soberania, facilidades e comodidade aos terroristas instalados no território afegão, o governo Taliban violou todas as regras e leis internacionais de combate ao terrorismo. Buscando atacar, enfraquecer, limitar e/ou acabar com o terrorismo, os Estados interventores no Afeganistão cumpriram as regras e leis internacionais sobre o tema. Assim, é legítima e justa a guerra contra o terrorismo, porque tal ação está amparada pelo Direito Internacional, pela Carta das Nações Unidas e pelas Resoluções do Conselho de Segurança, que em momento algum rejeitou a intervenção militar no Afeganistão, reafirmou o combate ao terrorismo e reconheceu o direito a autodefesa, individual ou coletiva, para fazer frente ao terrorismo, maléfico a toda à comunidade internacional.

Palavras-chave: Afeganistão. Terrorismo. Intervenção. Guerra justa.

\section{Abstract}

Afghanistan was admitted to the UN in the $40 \mathrm{~s}$, with a commitment to comply with the UN Charter. Wrapped in internal and external conflicts in the 70s and 80s, took control of most of Afghanistan the Taliban, the islamist group that has allowed the proliferation of radical islamist groups in Afghanistan. During this period, terrorists and terrorist groups like Al-Qaeda, Osama Bem Laden and his associates settled in Afghanistan without fighting the Taliban government, foundations for the structure of terrorist cells, terrorist training and planning of terrorist attacks. The Security Council, invoking Chapter VII of the Charter of the United Nations, more than once asked the Taliban government, terrorists and terrorist groups to respect International Law, UN Charter and resolutions as the terrorism. Nothing has been done by the parties on the issue. After the attack of september 11, 2001, the U.S. had intenvenção military in Afghanistan. The United States has relied on s. 51 of the UN Charter to justify military action. The Security Council has recognized the right of self-defense against terrorism. According to the theory of just war, war is legitimate to use force if connstitui defenses, how to ensure peace and security and alternative 
necessary to deal with the enemy. In the case of the intervention in Afghanistan, the International Law, UN Charter and Security Council resolutions that condemned and still condemn terrorism and recognize the right of self-defense, individual or collective, have always been dissatisfied by the government of the Taliban, Al-Qaeda, Osama Bem Laden and his associates. On the other hand, in accordance with resolutions of the Security Council, the fight against terrorism is an obligation for the members of the United Nations, under International Law, the UN Charter and Security Council resolutions itself, an act of terrorism against the entire international community. Ensure the sovereignty, facilities and comfort to terrorists installed in Afghanistan, the Taliban government has violated all international rules and laws to fight terrorism. Seeking to attack, weaken, limit and / or stop terrorism, governments intervene in Afghanistan was in accordance with international rules and laws on the subject. Thus, it is legitimate and just war against terrorism, because such action is supported by Interancional right by the Charter of the United Nations and the resolution of the Security Council, at no time rejected military intervention in Afghanistan, reaffirmed the fight against terrorism and recognized the right of self-defense, individual or collective, in the fight against terrorism, the harm to the entire international community.

Keywords: Afghanistan. Terrorism. Zone. The Just war.

A avaliação do tema proposto tem início na Resolução 8/46, adotada pelo Conselho de Segurança das Nações Unidas, e que recomendou a admissão do Afeganistão como Membro das Nações Unidas.

$\mathrm{Na}$ oportunidade, o Conselho de Segurança assim decidiu por maioria ampla, com 10 votos a favor, nenhum contra e uma abstenção (Austrália).

O Afeganistão, a partir deste marco legal, passou a integrar os quadros das Nações Unidas, devendo adotar todas as diretivas da Carta das Nações Unidas.

Em dezembro de 1979, o Afeganistão foi invadido pela então União Soviética (URSS), em razão das disputas políticas entre blocos comunistas nacionais após o golpe comunista no país deflagrado em 1978.

Este episódio, que conduziu o país a uma guerra entre nações por cerca de 10 anos, promoveu uma unificação temporária entre as forças nacionalistas locais, um apoio ao Afeganistão dos países islâmicos vizinhos, uma aproximação dos Estados Unidos com a China e alguns países islâmicos (como Paquistão, Egito e Arábia Saudita), e o início da guerra civil no Afeganistão, após a saída da União Soviética (GASPAR, 2001). 
Neste cenário de guerra civil, em que os comunistas, as guerrilhas e as brigadas internacionalistas islâmicas baseadas na Al-Qaeda disputaram o poder político, econômico e religioso no Afeganistão, os Taliban passaram a controlar substancial parte do território do Afeganistão, imprimindo no país o fundamentalismo islâmico, e permitindo aos grupos radicais islâmicos basearem-se em seu território, entre os quais a Al-Qaeda (MARSDEN, 2002).

Diante do conflito interno no Afeganistão, o Conselho de Segurança aprovou a Resolução 622/88, recomendando o envio de oficiais das Nações Unidas para atuarem em bom ofício no Afeganistão, avaliando a situação local, missão que teve o seu prazo de atuação prorrogado por mais 2 meses através da Resolução 647/90.

Dominando a maior parte do território afegão, os Taliban governaram com forte matriz islâmica (embora não tenha sido este o seu objetivo principal ao conquistar pela força o poder estatal (ROY, 2004)), com autoritarismo e de maneira ortodoxa, não trabalhando para conter o conflito interno armado, o que levou a imperar no Afeganistão uma alta violência.

Atento a esta questão, foi aprovada a Resolução 1076/96 do Conselho de Segurança, em que se manifestava grande preocupação com a continuação e a intensificação do conflito armado no Afeganistão, com vítimas civis, refugiados e pessoas deslocadas, e com a discriminação de gêneros e violações de direitos humanos.

Registrou o Conselho de Segurança, na assentada, que a situação no Afeganistão colocava em perigo a estabilidade e o desenvolvimento pacífico da região, e que a continuação do conflito no Afeganistão criava um terreno fértil para o terrorismo, desestabilizando a região e a comunidade internacional.

Em 7 de agosto de 1998, Nairobi (Quénia) e Dar-es-Salaam (Tanzânia) sofreram atos de terrorismo internacional, tendo o Conselho de Segurança adotado a Resolução 1189/98 em que se condenava o terrorismo.

Para o Conselho de Segurança, esses atos têm efeitos adversos sobre as relações entre os Estados, bem como ameaça a manutenção da paz e a segurança internacional.

Para o Conselho de Segurança, ainda, no caso em avaliação, competia à comunidade internacional eliminar o terrorismo internacional em todas as suas formas e manifestações, já que tal compromisso estava em conformidade com a Carta das Nações Unidas, sendo que todos os Estados-Membros da ONU deveriam se abster de organizar, instigar, auxiliar atos terroristas em território próprio ou em outros Estados, bem como (Estados e Instituições Internacionais) deveriam cooperar na busca dos terroristas responsáveis pelos atos de terrorismo ora ocorridos, levando-os a julgamento e eventual punição. 
Dias depois, o Conselho de Segurança aprovou a Resolução 1193/98, que apontava extrema preocupação com a persistência de terroristas no território do Afeganistão, exigindo que as facções afegãs se abstivessem de hospedar e treinar terroristas e suas organizações, pondo fim também às atividades ilegais relacionados com a produção de drogas e o tráfico internacional.

Consideravelmente específica para o Afeganistão, os Taliban continuaram ignorando as decisões do Conselho de Segurança.

Neste mesmo ano, o Conselho de Segurança voltou a expressar profunda preocupação com a continuação do conflito no Afeganistão, o que representava uma ameaça cada vez mais grave à paz e a segurança regionais e internacional, temas tratados na Resolução 1214/98.

Na matéria, ainda, o Conselho de Segurança declarou que o território afegão, controlado pelos Taliban, não poderia servir de abrigo para treinamento de terroristas e para o planejamento de atos terroristas, sendo um compromisso dos Estados-membros da ONU a erradicação do terrorismo internacional como medida para o asseguramento e a manutenção da paz e da segurança, no que voltou a exigir que os Taliban não fornecessem local que possibilitasse treinamento para terroristas internacionais e suas organizações, e que todas as facções afegãs cooperassem com os esforços para processar os acusados de atos de terrorismo.

Descumpridas as decisões anteriores do Conselho de Segurança pelo governo Taliban, aprovou-se a Resolução 1267/99, em que se recordaram as convenções internacionais contra o terrorismo e, em particular, a obrigação dos Estados de cumprirem essas convenções, bem assim o dever de extraditarem e processarem terroristas.

Sobre o Afeganistão, de forma específica, mais uma vez o Conselho de Segurança condenou o uso contínuo do território afegão utilizado para o abrigo, o treinamento de terroristas e o planejamento de atos terroristas, lamentando que os Taliban continuassem a fornecer refúgio para Osama bin Laden, permitindo que ele e seus associados utilizassem o território afegão como campo de treinamento de terroristas e base de operação do terrorismo internacional.

Na oportunidade, lembrou o Conselho de Segurança, também, que Osama bin Laden e seus associados foram indiciados pelos Estados Unidos da América pelo terrorismo nas embaixadas de Nairobi (Quénia) e Dar es Salaam (Tanzânia), e que existia pedido aos Taliban para entrega-los para julgamento.

Atuando sob o Capítulo VII da Carta das Nações Unidas, o Conselho de Segurança decidiu, em síntese, que os Taliban deveriam cumprir as Resoluções do Conselho; que deveriam cessar o fornecimento de abrigo e local de treinamento para terroristas internacionais; que deveriam tomar medidas para levar à justiça pessoas acusadas de infrações terroristas; e exigiu a entrega de Osama bin Laden e seus associados às autoridades competentes de um país que sofrera atentado terrorista ou onde fora instaurado os indiciamentos por atos terroristas. 
O governo Taliban no Afeganistão continuou a descumprir as decisões do Conselho de Segurança na matéria.

Em seguida, na Resolução 1269/99, registrou o Conselho de Segurança que não há justificativa para atos de terrorismo (que independem de motivação), e que as Resoluções pertinentes da Assembléia Geral (49/60), de conhecimento e observância de toda a comunidade internacional, são contrárias ao terrorismo, tendo a ONU, via Assmbléia Geral em 1994, firmado Declaração sobre Medidas para Eliminar o Terrorismo Internacional, com base no respeito aos princípios da Carta das Nações Unidas e as normas de Direito Internacional, incluindo o respeito pelo Direito Humanitário Internacional e aos Direitos Humanos.

Condenando expressamente todos os atos, métodos e práticas terroristas, intitulando-os de criminosos e injustificáveis, independentemente de sua motivação, quando e por quem cometidos, em todas as suas formas e manifestações, particularmente aquelas que podem representar um ameaça à paz e a segurança internacionais, o Conselho de Segurança exortou todos os Estados a aplicarem plenamente as convenções internacionais de que são partes contra o terrorismo e encorajou a adesão de toda a comunidade internacional para a adoção das convenções pendentes, na aplicação de todos os meios de combate ao terrorismo, e na cooperação entre os Estados para o julgamento de terroristas.

No ano seguinte, o Conselho de Segurança aprova a Resolução 1333/00, tratando das convenções internacionais contra o terrorismo e das obrigações dos Estados em cumprirem o Direito Internacional, com o dever extraditarem e/ou processarem terroristas.

Preocupado com a situação no Afeganistão, registrou o Conselho de Segurança que os Taliban continuavam a conferir abrigo para terroristas, permitindo a utilização do território afegão como base terrorista (para fins de treinamento e planejamento de atos terroristas); que continuam a fornecer refúgio para Osama bin Laden, que foi indiciado (juntamente com seus associados) pelo governo dos Estados Unidos da América pelo ataque terrorista das embaixadas em Nairobi (Quénia) e Dar es Salaam (República Unida da Tanzânia) e por conspirarem contra a vida de americanos fora dos Estados Unidos; que existia pedido para a entrega do terrorista para julgamento, o que não foi atendido pelos Taliban.

Atuando sob o Capítulo VII da Carta das Nações Unidas, decidiu o Conselho de Segurança, expressamente, exigir dos Taliban o cumprimento da Resolução $1267 / 99$, para que deixassem de fornecer refúgio e treino a terroristas internacionais e suas organizações, e tomassem medidas eficazes e apropriadas para combater as bases terroristas no território afegão, entregando Osama bin Laden e seus associados às autoridades competentes.

Embora membro da ONU, portanto, sujeito às decisões do Conselho de Segurança, o governo Taliban no Afeganistão continuou silente na matéria. 
Na Resolução 1363/01, o Conselho de Segurança reafirmou todas as as suas resoluções anteriores e, mais uma vez, atuando sob o Capítulo VII da Carta das Nações Unidas, açulou todos os Estados-Membros da ONU, nos termos da Carta das Nações Unidas, a cumprirem integralmente as medidas impostas pelas Resoluções $1267 / 99$ e 1333/00.

Em 11 de setembro de 2011, no território americano, ocorreram os atentados terroristas suicidas perpetrados, segundo acusão do governo dos Estados Unidos da América, pela Al-Qaeda, cuja base operacional era no Afeganistão e cuja liderança terrorista era de Osama bin Laden.

Não obstante Osama Bin Laden tenha negado a sua participação nos atentados terroristas, através da rede de televisão Al Jazeera, videos posteriores foram divulgados com imagem e som, cujas falas atribuiram-se a Osama bin Laden (não negado), e que tratavam dos atentados terroristas do 11 de setembro com terroristas que participaram diretamente dos ataques, como os apresentados pela CNN em 2001, a MSNBC em 2004 e a CBC News em 2006.

No dia seguinte (12/09/2001) aos atentados terroristas, o Conselho de Segurança das Nações Unidas (ONU) adotou a Resolução 1368/01, em que se reafirmava os propósitos e princípios da Carta das Nações Unidas, repudiava o terrorismo, reconhecia o direito (individual ou coletivo) de autodefesa em conformidade com a Carta das Nações Unidas e condenava o ataque terrorista que ocorrera em 11 de setembro de 2001 em Nova York, Washington - DC, e na Pensilvânia.

Na oportunidade, o Conselho de Segurança instou todos os Estados a trabalharem urgentemente em conjunto para trazer à justiça os autores dos atos terroristas, organizadores e patrocinadores destes ataques terroristas, e sublinhou que os responsáveis pela ajuda, apoio ou proteção aos autores, organizadores e patrocinadores destes eventos seriam responsabilizados em suas ações.

Os Estados Unidos da América, em outubro de 2001, após aprovação do Congresso americano, intervém no Afeganistão através da formulação de sua política internacional de "Guerra ao Terror", argumentando que existiam provas da atuação da Al-Qaeda e de Osama bin Laden nos atentados terroristas de 11 de setembro, todos com bases operacionais no território afegão governado pelos Taliban.

Invocando o art. 51 da Carta das Nações Unidas para justificar a ação militar (TELES, 2003), o governo americano anunciou ações preventivas e preemptivas (TOMÈ, 2004), traçando a partir daí uma estratégia de política internacional realista (SOUZA, 2005), na medida em que as posições políticas, econômicas e militares foram tomadas unilateralmente, à revelia da comunidade internacional. 
No Direito Internacional contemporâneo prevalece o Princípio Geral da Proibição da Guerra, estabelecido na Carta das Nações Unidas, que, em seu art. $2^{\circ}$, $\mathrm{n}^{\circ} 4$, veda a ameaça ou uso da força nas relações internacionais, salvo algumas exceções, como a do art. 51, em que se reconhece o direito natural à legítima defesa, e o art. 39 e seguintes do Capítulo VII, em que se reconhece as sanções militares por decisão do Conselho de Segurança.

Segundo Francisco de Vitória (1998), há guerra justa quando se fazem todas as coisas necessárias para se alcançar a paz e garantir a segurança, inclusive no território inimigo se for necessário para evitar o perigo que cidadãos e inimigos externos possam provocar.

Neste contexto, a ação militar americana e de seus aliados no Afeganistão se revestiria de uma "guerra justa", já que se buscou todos os meios de se garantir a segurança de seu território e de seus cidadãos, mesmo que a incursão militar tenha ocorrido em outro Estado, cujo território e governo amparavam bases e ações de grupos terroristas.

Embora as Resoluções do Conselho de Segurança não tenham afirmado expressamente que os Estados Unidos da Amárica e seu aliados tinham autorização para promoverem ações militares no Afeganistão, as Resoluções já tratavam da questão do terrorismo internacional e do fato de que o governo Taliban estava desde muito tempo descumprindo as decisões do Conselho.

Ademais, as Resoluções não rejeitaram em momento algum o argumento da legítima defesa do governo americano para a legitimidade da intervenção militar no Afeganistão.

Nesta linha, os Estados Unidos e seus aliados não inflingiram o Direito Internacional, mesmo porque a Resolução 1368/01 do Conselho de Segurança repudiou o terrrismo de 11 de setembro e reconheceu o direito (individual ou coletivo) de autodefesa em conformidade com a Carta das Nações Unidas.

Assim, tomando-se a Teoria da Guerra Justa, o direito de guerrear dos Estados Unidos da América foi legítimo, já que o regime Taliban forneceu à Al-Qaeda e a Osama Bin Laben todas as vantagens da soberania, sobretudo uma base territorial para a preparação dos ataques terroristas ao território americano (WALZER, 2004).

Atacar bases terroristas no Afeganistão, campos de treinamento e estrutura militar dos Taliban, Al-Qaeda e de Osama Bin Laden, procurar, deter e julgar terroristas e colaboradores de atos terroristas do 11 de setembro, também seriam atos legais de uso da força em legítima defesa a justificar a intervenção no território afegão pelo governo americano e seus aliados, na busca da satisfação destes objetivos (TELES, 2003).

Demais, decisões do Conselho de Segurança constituem uma das espécies de fontes do Direito Internacional.

Há decisões do Conselho de Segurança que são verdadeiras leis (AMARAL, 2005). 
Desde a adoção da Resolução 1076/96, passando pelas Resoluções 1189/98, 1193/98, 1214/98, 1267/99, 1269/99, 1333/00, 1363/01 e, especialmente, a 1368/01, o Conselho de Segurança apresentara preocupação com a situação do Afeganistão, com o estabelecimento de bases terroristas no território afegão, com a omissão do governo Taliban na matéria, e com o compromisso de todos os Estados-membros da ONU com o combate ao terrorismo.

Atuando sob o Capítulo VII da Carta das Nações Unidas, o Conselho de Segurança destacara, por várias vezes, a obrigação de todos os Estados-Membros da ONU, nos termos da Carta das Nações Unidas, de cumprirem integralmente as medidas impostas por suas Resoluções, o que foi ignorado pelo governo Taliban no Afeganistão.

Deste modo, embora a Resolução 1368/01 não tenha autorizado expressamente o uso da força militar pelos Estados Unidos da América e seus aliados, ocorreu o reconhecimento pelo Conselho de Segurança do direito (individual ou coletivo) de autodefesa em conformidade com a Carta das Nações Unidas, o que legitima a utilização de força militar na promoção de um conflito armado amparado pelo Direito Internacional, portanto, a possibilidade legítima de se fazer uma "guerra justa". de outro modo.

Para Francisco de Vitória (1998), há guerra justa quando não se pode agir

$\mathrm{Na}$ espécie, não foi dado ao governo americano, para salvaguardar o seu território e a integridade de seus cidadãos, outra forma senão a de promover um contra-ataque a um país cujo governo, os Taliban, reconhecidamente pela comunidade internacional e declarado pelo Conselho de Segurança, permitia o uso do território afegão para a construção de bases por grupos terroristas, treinamento e planejamento de atos terroristas em todo o mundo, em especial para a Al-Qaeda e para Osama Bin Laden.

Segundo Franscisco de Vitória (1998), se se age conforme o direito de guerra, tudo está a favor do justo direito de se fazer uma guerra justa.

Asssim, agindo conforme a Carta das Nações Unidas e nos termos das Resoluções do Conselho de Segurança, em especial a Resolução 1368/01, é legítimo o uso da força militar americana no Afeganistão para combater o terrorismo internacional em todas as suas formas, sobretudo contra os Taliban, a Al-Qaeda, Osama bin Laden e seus associados.

Vale destacar que após a intervenção militar no território afegão pelos Estados Unidos da América e seus aliados, foi aprovada a Resolução 1373/01 pelo Conselho de Segurança, e que reafirmara as Resoluções 1269/99 e 1368/01 e o direito (individual ou coletivo) de autodefesa reconhecido na Carta das Nações Unidas.

Na Resolução 1372/01, e atuando sob o Capítulo VII da Carta das Nações Unidas, decidiu o Conselho uma série de medidas extremas, dos quais tem-se: 
a) todos os Estados deveriam prevenir e reprimir o financiamento de quaisquer atos de terrorismo;

b) criminalizar a provisão ou a coleta intencional, por qualquer meio, direta ou indiretamente, de fundos por seus nacionais ou por seu território com a intenção de que os fundos são utilizados, ou conscientementeque estes fundos serão usados para perpetrar atos de terrorismo;

c) congelar sem demora os fundos e outros ativos financeiros ou direitos econômicos de pessoas que cometam ou tentem cometer atos terroristas ou participar ou facilitar a comissão, de entidades de propriedade ou controladas, direta ou indiretamente por tais pessoas e pessoas e entidades agindo em nome de tais pessoas e entidades ou menos, incluindo fundos provenientes ou gerados por bens pertencentes ou controlados direta ou indiretamente por tais pessoas e outras pessoas e entidades a eles associados; d) proibir seus nacionais ou a qualquer pessoa ou entidade que está em seus territórios de disponibilizar quaisquer fundos, ativos financeiros ou recursos econômicos ou serviços financeiros e outros serviços relacionados, direta ou indiretamente disponível para as pessoas que cometem ou tentam cometer atos de terrorismo ou facilitar a comissão ou participar, de entidades de propriedade ou controle direto ou indireto dessas pessoas, e pessoas e entidades agindo em nome dessa pessoa ou sob suas ordens;

e) abster-se de fornecer qualquer apoio, ativo ou passivo, a entidades ou pessoas envolvidas no cometimento de atos de terrorismo, inclusive suprimindo o recrutamento de membros de grupos terroristas e eliminando o fornecimento de armas aos terroristas;

f) tomar as medidas necessárias para prevenir atos de terrorismo, incluindo este aviso o mais rápido possível para outros Estados por intercâmbio de informação;

g) negar refúgio seguro para aqueles que financiam, planejam ou cometem atos de terrorismo, ou apoiar tais atos, ou providenciar abrigo para esses fins;

h) impedir que aqueles que financiam, planejam, facilitam ou cometem atos de terrorismo utilizando seus respectivos territórios para propósitos contra outros Estados ou seus cidadãos;

i) garantir o julgamento de qualquer pessoa envolvida no financiamento, planejamento, preparação ou perpetração de atos terroristas ou que fornece apoio a tais atos, e que, para além de quaisquer outras medidas de execução tomadas contra essas pessoas, esses atos constituem atos criminosos contra as leis severas e as leis nacionais dos outros e que a punição seja adequada à gravidade desses atos; 
j) se mutuamente, o maior grau de auxílio em relação a investigações ou processos criminais relacionados com o financiamento de atos terroristas ou apoiá-los, particularmente para obtenção de provas em sua posse e que são necessárias nestes procedimentos;

k) impedir a movimentação de terroristas ou grupos terroristas por eficácia dos controles de fronteira e controle na emissão de identidade e de viagem, e tomar medidas para prevenir a falsificação, uso ilegal e fraudulenta de documentos de identidade e de viagem;

1) encontrar meios de intensificar e acelerar a troca de informações operacionais, especialmente em relação as ações ou movimentos de terroristas ou redes terroristas;

m) documentos de viagem alteradas ao tráfego ilegalmente ou forjados de armas, explosivos ou materiais perigosos, o uso de tecnologia de comunicações por grupos terroristas e ameaça representada pela posse de armas de destruição em massa para grupos terroristas;

n) trocar informações, em conformidade com o direito internacional e direito interno e cooperar em assuntos administrativos e judiciais para impedir cometer atos de terrorismo;

o) cooperar, particularmente por meio de acordos bilaterais e multilaterais e das convenções acordos, para prevenir e reprimir ataques terroristas e agir contra os perpetradores de tais atos;

p) tornar-se as partes o mais rapidamente possível às convenções e protocolos convenções e protocolos relativos ao terrorismo, nomeadamente a Convenção Para a Supressão do Financiamento do Terrorismo;

q) aumentar a cooperação e implementar integralmente as convenções e protocolos internacionais relativos ao terrorismo, bem como as Resoluções do Conselho de Segurança 1269/99 e 1368/01;

r) tomar as medidas apropriadas, em conformidade com as disposições da legislação nacional pertinente e do direito internacional, incluindo normas de direitos humanos internacionais, antes de conceder status de refugiados, a fim de assegurar que os requerentes de asilo não tenham planejado ou facilitado atos de terrorismo, ou participado de sua comissão;

s) assegurar, em conformidade com o direito internacional, que o estatuto de refugiado não é abusado por autores, organizadores ou patrocinadores do terrorismo, e que a alegação não é de reconhecido de motivação política como motivo para recusar pedidos de extradição suspeitos de terrorismo.

Vê-se, pois, que a Resoluçao 1373/01 corroborou os termos das Resoluções anteriores contra o terrorismo, não apresentando qualquer recomendação ou rejeição ao governo americanco e seus aliados sobre a intervenção militar no Afeganistão. 
Por sua vez, o Conselho de Segurança voltou a declarar que atos, métodos e práticas terroristas são contrárias à propósitos e princípios das Nações Unidas e que o financiamento de atos de terrorismo, planejamento e incitação de atos terroristas são igualmente contrários ao propósitos e princípios das Nações Unidas.

Ao contrário da deslegitimação, as Resoluções do Conselho de Segurança sinalizaram que a "guerra ao terror" é uma guerra justa porque amparada pelo Direito Internacional, na medida em que o terrorismo viola tanto Acordos e Convenções Internacionais sobre o tema quanto à Carta das Nações Unidas, e, por fim, as Resoluções do próprio Conselho.

Neste linha, a Resolução 1377/01 do Conselho de Segurança buscou implemenatar uma ação global para combater o terrorismo, e, nos termos da Resolução 1373/01, conclamou os Estados a lutarem contra o terrorismo.

Já na Resolução 1378/01 o Conselho de Segurança apoiou os esforços internacionais para erradicar o terrorismo com base na Carta das Nações Unidas, apoiou o povo afegão por buscar substituir os Taliban na governança do país, e condenou os Taliban por permitir que o Afeganistão fosse usado como base territorial de terroristas e por ter dado refúgio a Osama Bin Laden.

Assim, manifestando absoluta reprovação pelo terrorismo internacional, pelo governo Taliban, pela Al-Qaeda e por Osama Bin Laden, e registrando tal reprovação em uma Resolução, o Conselho de Segurança legitima, à luz do Direito Internacional, ações necessárias de qualquer Estado-membro da ONU no combate ao terrorismo, inclusive o conflito armado por estar conforme o Direito Internacional e a Carta das Nações Unidas.

Em razão da complexidade da situação no Afeganistão, o Conselho de Segurança adotou a Resolução 1383/01, congratulando-se com os esforços para o restabelecimento das instituições governamentais permanentes no Afeganistão, uma tentativa de se modificar o quadro de instabilidade na região.

Em seguida, na Resolução 1386/01, o Conselho de Segurança apoiou os esforços internacionais para erradicar o terrorismo, em conformidade com a Carta das Nações Unidas, e, atuando ao abrigo do Capítulo VII da Carta das Nações Unidas, autorizou o estabelecimento temporário de uma Força Internacional de Assistência à Segurança para apoiar a autoridade interina afegã na manutenção da segurança no território do Afeganistão, conclamando os Estados a contribuirem nesta tarefa e dispondo que os Estados que participassem da Força Internacional de Assistência de Segurança poderiam tomar todas as medidas necessárias para cumprir o seu mandato.

Por certo, quando se estabelece a premissa de adoção de todas as medidas necessárias ao cumprimento do mandato, tem-se o manejo de ações políticas, econômicas e militares, a sustentar as operações de combate ao terrorismo e de reconstrução do Estado que sofre a intervenção, tudo dentro dos princípios, regras e leis internacionais. 
Na Resolução 1390/02, reafirmando as suas resoluções anteriores sobre o Afeganistão, em particular as Resoluções 1378/01, 1383/01, 1368/01 e 1373/01, o Conselho de Segurança reiterou o seu apoio na erradicação do terrorismo internacional, em conformidade com a Carta das Nações Unidas, e voltou a condenar os ataques terroristas em Nova York, Washington e Pensilvânia em 11 de setembro de 2001.

Observando que a Al-Qaeda e Osama Bin Laden continuavam a realizar atividades de apoio ao terrorismo internacional, e que os Taliban não tinham respondido às Resoluçoes do Conselho de Segurança, condenou os Taliban por permitirem que o Afeganistão fosse usado como base para terroristas, já que atos de terrorismo internacional constituem uma ameaça à paz e segurança internacionais.

Vê-se, pois, que após a intervenção militar no Afeganistão o Conselho de Segurança continuou tratando do terrorismo como uma ameação à ordem mundial, por afrontar o Direito Internacional, a Carta das Nações Unidas e as suas Resoluções.

Sempre preocupado com a situação no Afeganistão, na Resolução 1401/02 o Conselho de Segurança apoiou a criação, por um período inicial de 12 meses a partir a data de adoção da referida resolução, da Missão de Assistência das Nações Unidas no Afeganistão (UNAMA).

Em 2002, na Resolução 1419, o Conselho de Segurança congratulou-se com a eleição, pela Loya Jirga de emergência, do Chefe de Estado o presidente Hamid Karzai, e do estabelecimento da Autoridade de Transição no Afeganistão.

Condenando os ataques a bomba em Bali (Indonésia) em 12 de outubro de 2002, e considerando que tais atos, como qualquer ato de terrorismo internacional, constituem uma ameaça à paz e a segurança internacionais, o Conselho de Segurança registrou tais fatos na Resolução 1438/02, para reafirmar os propósitos e princípios da Carta das Nações Unidas e suas anteriores Resoluções pertinentes ao terrorismo.

Episódio também reprovável foi a tomada de reféns em Moscou (Rússia) no dia 23 de outubro de 2002, em que o Conselho de Segurança o considerou ato de terrorismo internacional, que ameaça a paz e segurança interna e internacional, com ferimento da Carta das Nações Unidas, e, assim, adotou a Resolução 1440/02 para o caso.

Seguindo a mesma linha de legitimação do combate ao terrorismo segundo o Direito Internacional, o Conselho de Segurança, quase sempre atuando ao abrigo do Capítulo VII da Carta das Nações Unidas, editou outras Resoluçoes sobre o tema e sobre o Afeganistão.

Na Resolução 1444/02 o Conselho de Segurança apoiou os esforços internacionais para erradicar o terrorismo e congratulou-se com a Autoridade Provisória Afegã pela colaboração com a Força Internacional de Assistência à Segurança. 
Segundo a Resolução 1450/02, o Conselho de Segurança condenou o atentado à bomba terrorista em Paradise Hotel em Kikambala (Quênia) e a tentativa de ataque de mísseis Flight 582 da Arkia Israeli Airlines em Mombasa (Quênia) no dia 28 de novembro de 2002 , bem assim outros atos terroristas recentes em vários países.

Já na Resolução 1452/02 o Conselho de Segurança reiterou expressando a sua determinação de assegurar o cumprimento das obrigações pelos Estados-membros da ONU de combaterem o terrorismo.

Apresentando evoluções institucionais, o Conselho de Segurança reconheceu a Administração Transitória como o único governo legítimo do Afeganistão até as eleições democráticas em 2004, registrando tal ato na Resolução 1453/02.

No ano de 2003, volta o Conselho de Segurança a tratar do terrorismo e em especial dos Taliban, da Al-Qaeda e de Osama Bin Laden, ao dispor, na Resolução 1455/03, que era obrigação imposta a todos os Estados-membros da ONU a implementação da Resolução 1373/01 e o combate ao terrorismo em conformidade com as Resoluções do Conselho de Segurança na matéria, com as regras da Carta das Nações Unidas e do Direito Internacional.

O combate ao terrorismo permaneceu, pois, em pauta nas reuniões do Conselho de Segurança, e o teor de suas Resoluções sobre o tema apontaram na direção da legitimação de qualquer ação política, econômica ou militar promovida por qualquer Estado contra o terrorismo internacional e os terroristas, razão pela qual o conflito armado, se instaurado segundo esta orientação, seria legítimo, portanto, uma guerra travada nestes termos seria uma "guerra justa" porque amparada pelo Direito Internacional e pelas Resoluções do Conselho de Segurança.

Na Resolução 1456/03 o Conselho de Segurança manisfestou grande preocupação com a possibilidade de terroristas e grupos terroristas terem acesso a armas nucleares, químicas, biológicas e outras potencialmente letais, pelo que conclamou os Estados a apertarem os controles destes materiais, já que, no mundo cada vez mais globalizado, tornou-se cada vez mais fácil para os terroristas a exploração de sofisticadas tecnologias, mecanismos de comunicações modernas e obtenção de novos recursos para os seus objetivos.

Lembrou o Conselho de Segurança, ainda, que o terrorismo só pode ser derrotado através de uma estratégia abrangente e realizada com a participação ativa e a colaboração de todos os Estados e Organizações Internacionais e Regionais, de acordo com a Carta das Das Nações Unidas e o Direito Internacional.

Em 7 de fevereiro de 2003 ocorreu o atentado à bomba em Bogotá (Colômbia), qualificado como um ato de terrorismo e de ameaça a paz e a segurança regional e internacional, levando o Conselho de Segurança a reafirmar o repúdio ao terrorismo na Resolução 1465/03. 
Aprovando a Resolução 1510/03, o Conselho de Segurança salientou a importância da Autoridade do Governo Central no Afeganistão, as ações de desarmamento, desmobilização e reintegração de todas as facções armadas e a reforma do setor de segurança no Afeganistão, incluindo a reconstituição do Exército Nacional Afegão e da Polícia Afegã, mas lembrou que a situação no Afeganistão ainda constituia uma ameaça para a paz e segurança.

Pela Resolução 1516/03 o Conselho de Segurança reafirmou a necessidade de combater por todos os meios, de acordo com da Carta das Nações Unidas, as ameaças à paz e segurança criadas por atos de terrorismo, e condenou os atentados cometidos em Istambul (Turquia) em 15 e 20 novembro de 2003, para, em seguida, exortar todos os Estados, em conformidade com as obrigações que lhes incumbem nos termos da Resolução 1373/01, que cooperassem nos esforços para que os autores, organizadores e patrocinadores destes ataques terroristas fossem encontrados e levados a julgamento.

Para firmar o combate ao terrorismo, o Conselho de Segurança, logo após o atentado de Istambul aprovou a Resolução 1526/04, e que recordou as suas Resoluções 1267/99, 1333/00, 1363/01, 1373/01, 1390/02, 1452/02 e 1455/03.

Os ataques a bomba em Madrid (Espanha) de 11 de março de 2004 pelo grupo terrorista ETA, mais um ato de terrorismo, foi reprovado pela Resolução 1530/04 do Conselho de Segurança.

Em seguida, pela Resolução 1535/04, o Conselho de Segurança reafirmou a sua determinação renovada para combater todas as formas de terrorismo, em conformidade com as suas responsabilidades sob da Carta das Nações Unidas, e lembrou que todos os Estados deveriam assegurar que as medidas tomadas para combater o terrorismo fossem levadas a efeito, pois que tais obrigações estão amparadas no Direito Internacional, incluindo o Direito Internacional relativo aos Direitos Humanos, aos refugiados e ao Direito Humanitário.

Como se vê, o Conselho de Segurança, na matéria, inovou na Resolução 1534/04, já que atribui aos Estados-membros da ONU o dever de combater o terrorismo na linha da proteção aos Direitos Humanos.

Congratulando-se com a Constituição aprovada pela Loya Jirga, em 4 Janeiro de 2004, que reflete a vontade do povo afegão para assegurar a transição em seu país para uma sociedade democrática e estável, e reafirmando que a Administração Transitória é o único governo legítimo do Afeganistão até as eleições democráticas a serem realizadas para a Presidência e para o Parlamento Afegão, o Conselho de Segurança, sempre atento aos acontecimentos no Afeganistão, editou a Resolução $1536 / 04$. 
Manifestando reservas aos Taliban e a Al-Qaeda, pouco depois o Conselho de Segurança aprovou a Resolução 1566/04, em que incitou os Estados a cooperarem plenamente com o Comitê contra a Terrorismo estabelecido pela Resolução 1373/01, bem como com o Comité de Sanções para os Taliba e a Al-Qaeda estabelecido pela Resolução 1267/99.

O atentados terroristas de Londres (Inglaterra) em 07 de julho de 2005 foram condenados pelo Conselho de Segurança através da Resolução 1611/05, e que encorajou todos os Estados, em conformidade com suas obrigações nos termos da Resolução 1373/01, a cooperarem ativamente nos esforços para encontrar e levar à justiça os autores, organizadores e patrocinadores dos atos terroristas.

Diante dos acontecimentos recentes, adotou o Conselho de Segurança a Resolução 1617/05, para reiterar a sua condenação inequívoca aos Taliban, a AlQaeda, a Osama Bin Laden, a indivíduos, grupos, empresas e entidades a eles associados, por atos de terrorismo, solicitando aos Estados um esforço na aplicação das medidas já adotadas contra todos.

Na Resolução 1618/05, adotada pelo Conselho de Segurança, expressou-se preocupação com a situação no Iraque.

O Conselho de Segurança, ao depois, pela Resolução 1623/05, reconheceu os desafios que o Afeganistão enfrentava em relação à situação da segurança em algumas partes do país, tendo a Força Internacional de Assistência à Segurança papel fundamental neste processo.

Atento ao terrorismo e definindo a aplicação do Direito Internacional na matéria, pela Resolução 1624/05 o Conselho de Segurança determinou que as medidas de proteção contidas na Convenção sobre os Refugiados e seus Protocolos não fossem aplicadas a qualquer um, posto que inaplicáveis aos terroristas.

Na oportunidade, o Conselho de Segurança considerou prioritária a assinatura da Convenção Internacional para a Supressão de Atos de Terrorismo Nuclear adotada pela Assembléia Geral.

Com a celebração do Pacto para o Afeganistão, firmado na Conferência de Londres, em que o Governo do Afeganistão e a comunidade internacional estreitaram os mecanismos de colaboração entre eles, o Conselho de Segurança, não obstante tenha elogiado o pacto, continuou expressando preocupação com a segurança no Afeganistão e o terrorismo perpetrado pelos Taliban e a Al-Qaeda, nos termos de sua Resolução 1707/06.

A reprovação pelos atos terroristas cometidos pelos Taliban, Al -Qaeda e outros indivíduos e grupos terroristas e seus colaboradores e financiadores, e a advertência aos Estados-membros da ONU para que combatam o terrorismo por todos os meios, foi reafirmada pelo Conselho de Segurança nas Resoluções 1735/06, 1662/06 e 1746/07. 
Já na Resolução 1776/07, o Conselho de Segurança condenou o uso de civis como escudos humanos pelos terroristas e congratulou-se com a conclusão da implantação da Força Internacional de Assistência à Segurança em todo o Afeganistão, no serviço de conferir segurança ao país, bem assim com a Organização do Tratado do Atlântico Norte (OTAN) pelas contribuições dadas à Resolução da situação de segurança no Afeganistão, para o êxito da operação "Liberdade Duradoura", o que foi reafirmado na Resolução 1833/08.

De fato, desde o início da intervenção militar no Afeganistão a OTAN se revelou um parceiro do governo americano e seus aliados nas incursões militares no Afeganistão, tendo invocado o art. $5^{\circ}$ do seu Estatuto para justificar o apoio militar aos Estados Unidos da América, já que o aliado tinha sofrido em 11 de setembro de 2001 ataques armados vindo do exterior (TELES, 2003).

Se o planejamento dos ataques terroristas aconteceu em território afegão, controlado pelos Taliban, e que abrigava bases terroristas da Al-Qaeda, de Osama Bin Laden e seus associados, a tese de ataque militar vindo do exterior foi levada a efeito pela OTAN, na medida em que os atos terroristas ocorreram possivelmente pela comodidade fornecida pelo governo afegão aos terroristas que construiram bases operacionais, treinaram terroristas e planejaram os atentados, tudo com a proteção da soberania do Estado Afegão.

Na Resolução 1805/08, o Conselho de Segurança felicitou aprovação pela Assembléia Geral da ONU da Estratégia Global da Organização das Nações Unidas Contra o Terrorismo, e a criação de uma Equipe Especial de luta contra o terrorismo para garantir a coordenação e a coerência das medidas tomadas pelo sistema das Nações Unidas contra o terrorismo.

Tratado como tema da ordem mundial, o terrorismo em todas as sua formas é repudiado pelas Nações Unidas pela via do Conselho de Segurança.

Pela Resolução 1806/08, o Conselho de Segurança parabenizou os esforços da Jirga na busca de uma paz sustentável para região, e o diálogo entre o governo do Afeganistão e o governo do Paquistão na busca destes mesmos propósitos.

Manifestando preocupação entre a relação do terrorismo internacional e o crime organizado transnacional, o tráfico de drogas e o tráfico de armas, o Conselho de Segurança chama a atenção dos Estados para o enfrentamento destas questões na Resolução 1817/08, que deveriam ser combatidas conforme as obrigações dos Estados de acordo com a Carta das Nações Unidas, em programas que estabeleçam a cooperação em níveis nacional, sub-regional, regional e internacional para fortalecer a resposta a este grave problema global.

Atento, ainda, ao mundo globalizado, bem como a utilização da internet para a disseminação, recrutamento, troca de informações, planejamento e emissão de ordens de ataques terroristas, o Conselho de Segurança incitou os Estados e as Instituições Internacionais para coordenarem ações objetivando parar, enfraquecer, isolar e neutralizar esta ameaça terrorista, cumprindo a sua Resolução 1822/08. 
Mais adiante, apontando a necessidade de tratar urgentemente da situação humanitária no país, na busca da melhoria da cobertura, qualidade e quantidade da ajuda humanitária, com a entrega eficiente, eficaz e oportuna da assistência humanitária à toda a população civil atingida pelo conflito armado no Afeganistão, e condenando os ataques terroristas contra a ajuda humanitária, o Conselho de Segurança adotou a Resolução 1868/09, conclamando todos a respeitarem plenamente as disposições do Direito Internacional Humanitário.

Já na Resolução 1890/09 o Conselho de Segurança voltou a condenar os atos terroristas dos Taliban, Al-Qaeda e outros grupos extremistas no Afeganistão que provocam entraves ao fornecimento de segurança, serviços básicos e ofensa aos direitos humanos e as liberdades fundamentais do povo afegão.

Na mesma linha, na Resolução 1904/09 o Conselho de Segurança condenou os casos de rapto e tomada de reféns cometidos por indivíduos, grupos, empresas e entidades associadas aos Taliban, Al-Qaeda e Osama Bin Laden, e o uso de civis como escudos humanos para atos terroristas, em completa violação ao Direito Internacional.

Na adoção da Resolução 1917/10, o Conselho de Segurança revelou satisfação com a declaração da Conferência de Londres e Cabul, por terem estabelecido prioridades para o progresso no Afeganistão, com base em uma estratégia abrangente que seria realizada pelo Governo afegão junto com a comunidade internacional, e na realização de eleições nacionais em 2010 no país, e reafirmou as Resoluções 1890/09 e 1904/09.

Preocupado com o combate à corrupção no Afeganistão, o Conselho de Segurança aprovou a Resolução 1943/10, solicitando do governo afegão esforços na matéria para promover a transparência e a melhoria da prestação de contas públicas, conforme o compromisso assumido na Conferência de Londres.

Ademais, prevista a condução, pelo governo do Afeganistão, das operações militares e policiais civis em seu território a partir do final do ano de 2014, lembrou o Conselho de Segurança da importância de o governo do Afeganistão avançar nas medidas para acabar com a impunidade e com o enfraquecimento das Instituições Públicas, em respeito a sua Constituição.

Reafirmando que o terrorismo não pode ser associado com nenhuma religião, nacionalidade, civilização ou grupo étnico, o Conselho de Segurança na Resolução 1963/10 voltou a consignar que terrorismo continua a ser uma grave ameaça à paz e segurança internacionais e ao gozo do desenvolvimento humano e socio-econômico de todos os Estados-Membros da ONU, e que a luta contra o terrorismo continua a ser uma prioridade na agenda internacional.

Nestes termos, o combate ao terrorismo pode ser considerado uma "guerra justa", na medida em que atos terroristas ameaçam toda a humanidade. 
Recordando as Resoluções 1674/06, 1738/06 e 1894/09, relativas à proteção de civis em conflito armado, o Conselho de Segurança na Resolução 1974/11 determinou as partes no conflito armado que tomassem providências para assegurar a proteção dos civis afetados, observando-se o Direito Internacional Humanitário e os Direitos Humanos.

Apoiando o processo de reestruturação do Afeganistão, na Resolução 1988/11 o Conselho de Segurança incentivou a reconciliação entre todos os afegãos, conforme delineado no Acordo de Bonn, na Conferência de Londres e de Cabul, lembrando que as condições para a reconciliação implicam em desistir da violência, não ter vínculos com organizações terroristas internacionais e respeitar a Constituição do Afeganistão, incluindo os direitos das mulheres e pessoas pertencentes às minorias.

Na Resolução 1989/11, o Conselho de Segurança enfatizou que as sanções são ferramentas importantes para, nos termos da Carta das Nações Unidas, manter e restaurar a paz e a segurança.

Por fim, no ano de 2012, o Conselho de Segurança aprovou a Resolução 2041, em que manifestou apoio ao processo de transição para que o governo do Afeganistão pudesse governar o país com segurança e de forma democrática, até o final do ano de 2014.

Enfatizando que o futuro do Afeganistão depende da paz, de uma economia sustentável, do não terrorismo, da não produção de narcóticos, no respeito ao Estado de Direito, lembrou a declaração da OTAN e do governo do Afeganistão sobre o estabelecimento de uma parceria duradoura para a manutenção da segurança, da necessidade, no âmbito da assistência humanitária, da observância dos princípios humanitários, e da situação de segurança no Afeganistão, devido às atividades terroristas levadas a cabo pelos Taliban, Al-Qaeda e outros grupos extremistas e violentos, armados e ilegais.

Por tudo, tem-se, até os dias de hoje, no Afeganistão, e conforme o Direito Internacional, diretivas devidamente autorizadas pelo Conselho de Segurança das Nações Unidas para o combate ao terrorismo.

Todas as ações políticas, econômicas, militares e humanitárias realizadas no Afeganistão, e que possam levar a paz e a segurança regional e internacional, foram avalizadas pelo Conselho de Segurança que, mesmo antes dos ataques terroristas do 11 de setembro, já repudiava o terrorismo internacional e o uso do território afegão para bases terroristas, em especial da Al-Qaeda, de Osama Bin Laden e seus associados, nada fazendo o governo Taliban para cessar tais atividades terroristas (de organização, treinamento e planejamento de atos terroristas), não obstante as Resoluções do Conselho de Segurança em sentido contrário. 
Por outro lado, e segundo o Conselho de Segurança através de suas Resoluções, o terrorismo deve ser combatido por todos os Estados-membros da ONU, nos termos da Carta das Nações Unidas e do Direito Internacional, isso porque o terrorismo representa um atentado não apenas ao Estado atacado, mas a toda comunidade internacional.

Sendo dever do Estado-membro da ONU combater o terrorismo, nos termos do Direito Internacional e em cumprimento à Carta das Nações Unidas e das Resoluções do Conselho de Segurança na matéria, é legítima qualquer ação política, econômica e militar realizada por um Estado que vise obstar, enfraquecer ou eliminar o terrorismo, mesmo que tais ações ocorram em outro território nacional, pois o terrorismo atinge toda a comunidade internacional.

Assim, o conflito armado nestes termos configura-se como "guerra justa", porque amparado pelo Direito Internacional, a Carta das Nações Unidas e as Resoluções do Conselho de Segurança sobre o terrorismo.

\section{REFERÊNCIAS}

AMARAL, Diogo Freitas do. Será o Direito Internacional verdadeiro Direito? In: Política Internacional. Lisboa, II Série, ${ }^{\circ} 27$ (fev. 2005).

FRANCISCO DE VITÓRIA. Sobre el poder civil. Sobre los índios. Sobre el derecho de guerra. Madri: Tecnos, 1998.

GASPAR, Carlos. Teorias das alianças. Política Internacional. IPRI. v. 3, n 24 , 2001.

MARSDEN, Peter. Os Talibã. Guerra e Religião no Afeganistão. Lisboa: Instituto Piaget, 2002.

ROY, Olivier. Afghanistan: La Difficile Reconstruction D'Un Etat. Cahier de Chaillot, Institut d'Etudes de Sécurité, n 73, 2004.

SOUZA, Fernando de (Dir). Dicionário de Relações Internacionais. Edições Afrontamento, CEPESE e autores, $n^{\circ}$ 954, 2005.

TELES, P. G. A intervenção estrangeira no Afeganistão e o Direito Internacional. Janus 2003: Anuário de Relações Exteriores. Lisboa: Edição Observatório de Relações Exteriores da UAL, 2003.

TOMÉ, Luís Leitão. Novo recorte geopolítico mundial. Lisboa: Edição UAL, 2004.

WALZER, Michael. A guerra em debate. Lisboa: Livros Cotovia, 2004.

www.un.org/es/documents/sc/index.shtml. Página visitada em 06 de junho de 2012. 